\title{
Study of Language Form in Silent Manga
}

\author{
Sayid Mataram ${ }^{1}$ \\ ${ }^{1}$ Visual Communication Design, Faculty of Fine Arts and Design, Universitas Negeri Solo, Surakarta, Indonesia \\ danangmataram@gmail.com (Sayid Mataram 1)
}

\begin{abstract}
Manga is a variety of comics that emerged from Japan that has a lot of fans in every part of the world. Silent manga appears as variations that appear with the construction of different elements with conventional comics. Symptom analysis in the construction of visual languages of comic elements was used as a way to reveal the difference. The theory of inner and outer layout of the Prima Tabrani Fine Language theory is an appropriate approach that could be used to see different element in the silent manga.
\end{abstract}

Keywords silent manga, internal composition, external composition, visual language, comic

\section{Introduction: Comics and Manga}

Comic is one form of art products that are becoming more popular today. The great comic genre of the West (Europe and America) as well as from the East (Japan) interact with each other in the world comic constellation. Cultural differences that then spawned a variety of comic variations. The differences can be seen for instance from the physical form, image style, genre, also in the preparation of comic elements.

Comic is translated as a picture story in Indonesian. Comics are stories visualized using images and other supporting elements. The function of comics is basically as a speech medium, which is comparable to the language (linguistics) which is also a speech medium. The analogy is intended to build the analogy of the structure of comic compilers. As one form of communication media, of course, comic can deliver a message, which in this case is from comic artist to comic reader.

Manga is the Japanese term for a comic, but the term later became popular as similar to one particular visual style. Nowadays, Manga has grown in as if invading culture in the world with its influence. One of the richness of this Manga culture is the emergence of silent Manga which is visually and literally translated as a Manga form that does not use phonogram (word/writing) in it.

The presence of silent manga presents a lot of anxieties about the construction of comic elements. Silent manga is somehow called into doubt as a form of comic because of the incompleteness of the fundamental elements. The absence of phonogram elements is quite disturbing because the perception of comic elements generally comes with its "standard" relations. It then becomes interesting when trying to categorize silent manga as a comic or not.

\section{Research Methodology}

The research was conducted in descriptive qualitative research which explored the case by purposive sampling. In this research, the researcher will discuss descriptively about silent manga case to be identified as comic category. Case studies mean "review process (proses mengkaji)" as well as "results of the review process (hasil dari proses pengkajian)" for one particular case (Denzin and Lincoln, 2009: 299-300). Because the forms of works have similar constructions between each other, the case studies of silent manga will be sampled randomly from the works on www.manga-audition.com as a site that hosts international-grade competition since 2013 which is soft file-based uploaded into it.

The analysis used in the form of a comic language with the analogy of the relation of the word element into a sentence. In one word, there are constituent elements in the form of morphemes and phonemes, then this element is analogically will exist as an element in every comic panel. Morpheme is the smallest element that has a meaning, while the phoneme is the smallest element in a word which is meaningless but affects the meaning (Budiman, 2011: 10). To 
become a sentence, then the word should be understood based on one particular structure rule, for example with the structure of SPOK (Subject - Predicate - Object - Adverb) sentence in Indonesian or the use of tense in English. The words are connected to one sentence or there is a process of cohesion. Cohesion in comics relates to the way in which panels are connected to one another (Saraceni, 2003: 37).

\section{Comic Structure in General}

Will Eisner defines the comic function as a way of speaking, either as entertainment or other functions such as instruction (Eisner, 1985: 139-146). Mario Saraceni explained that language has a constituent element of the basic form of the word, the comic has a constituent element of the basic form of an image (picture) and words (word) that serves as a content word, while the functions of functional word carried by a speech balloon, gutter, caption, and panel (Saraceni, 2003: 5- 1 0).

Scott McCloud mentions that comics are composed of images and other symbols, including, of course, the writings that have fallen in some order (McCloud, 2001: 8). Hikmat Darmawan completes McCloud's definition that comics are images or pictures coined in deliberate sequences intended to contain information and/or produce an aesthetic response within the reader (Darmawan, 2012: 37).

From Saraceni, McCloud and Darmawan's statement, it can be said that the comic compiler elements are content elements such as picture, word/phonogram, and functional elements such as speech bubble, caption, gutter, and panel. The analogy of words with morphemes and phonemes, it means assembling content and functional comic elements in one panel. The panels in one page are related to each other in cohesion into a meaningful panel in which follow the story line.

The problem arises when in the content element, one finds an important element in every panel to be incomplete repetitively, in this case is the absence of word element (word/phonogram). So that in each panel, it will be composed of image elements only. So, the comic structure will be inadequate and become a "handicap comic".
Table 1. Textual Comic Perspectives

\begin{tabular}{|c|c|c|}
\hline $\begin{array}{l}\text { Elements } \\
\text { of Comics }\end{array}$ & Elaboration & Comic Theory \\
\hline \multirow{3}{*}{ Picture } & Icon & Mario Saraceni \\
\hline & Character & \multirow{2}{*}{ Scott McCloud } \\
\hline & Settings & \\
\hline \multirow[b]{2}{*}{ Word } & Word & Mario Saraceni \\
\hline & $\begin{array}{l}\text { Phonograms (Di- } \\
\text { alog, Narration, } \\
\text { and Sound effects) }\end{array}$ & Scott McCloud \\
\hline $\begin{array}{c}\text { Speech } \\
\text { bubble } \\
\text { and } \\
\text { Caption }\end{array}$ & Frame of Word & Scott McCloud \\
\hline \multirow{3}{*}{ Panel } & $\begin{array}{c}\text { Frame of Mo- } \\
\text { ments }\end{array}$ & Scott McCloud \\
\hline & Inner layout & \multirow{2}{*}{ Primadi Tabrani } \\
\hline & Outer layout & \\
\hline
\end{tabular}

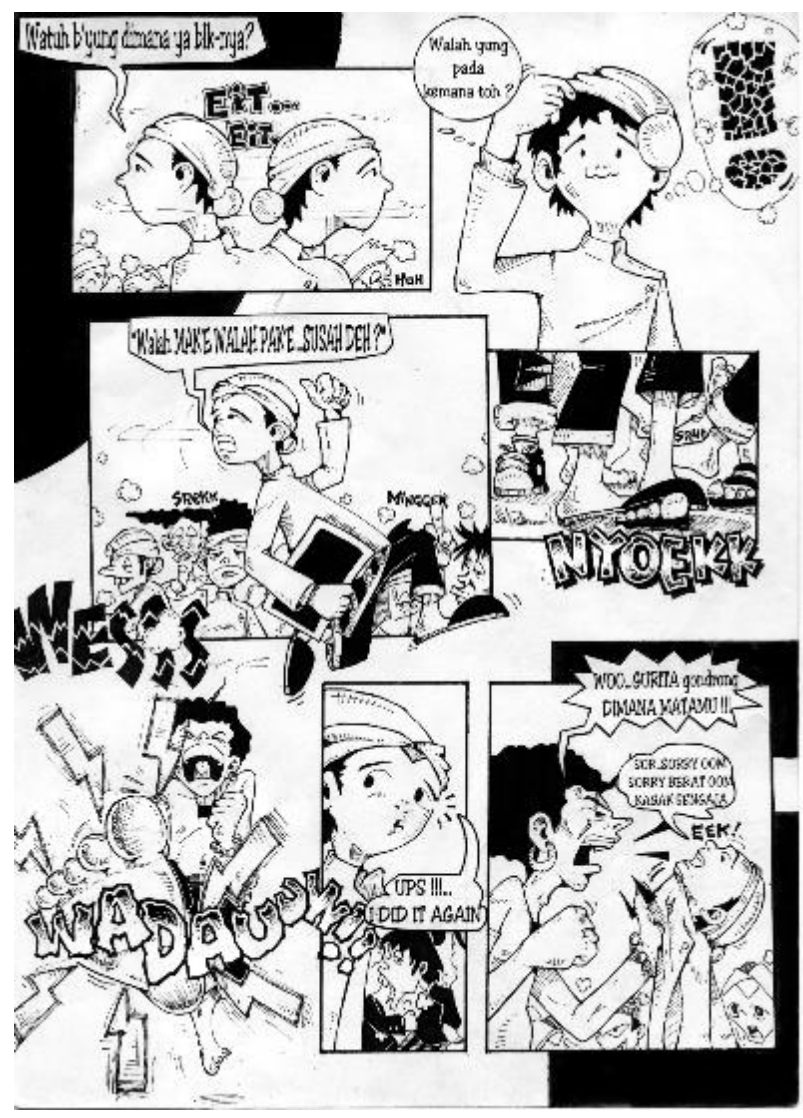

Figure 1. Comic of "Tigan Ngasak Batavia” by Qomik Workshop 


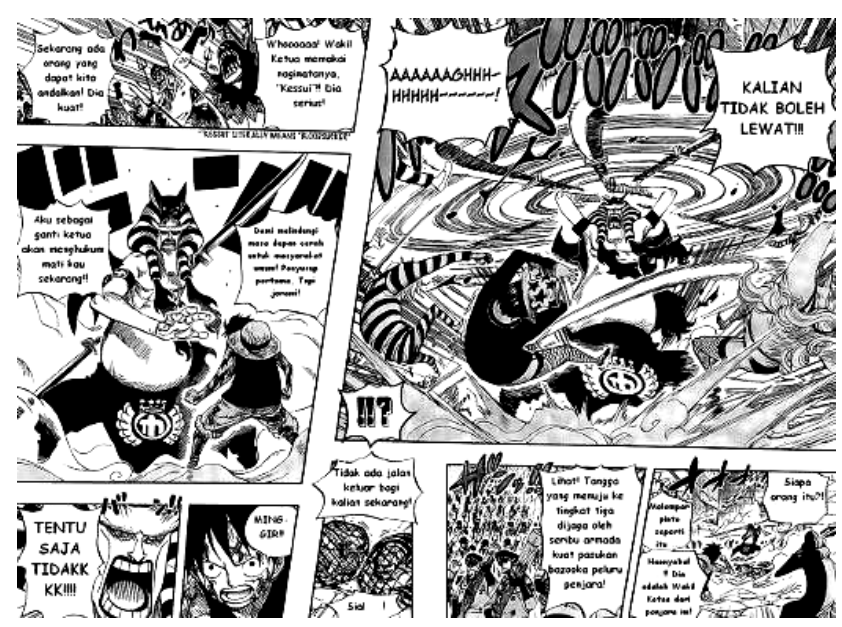

Figure 2. Manga One Piece by Eichiro Oda

Another perspective becomes necessary to judge that comic is a unity of its constituent elements, in which elements of one and the other are also closely related. It seemed as if it actually makes the comic to be as similar as to reliefs of temple or a Beber puppet, which also do not have any word (word/phonogram), but the meaning still can be captured through the relationships within each picture element in the relation between each panel. For that reason, then the researcher used the theory of language from Primadi Tabrani who see that comic is a unity of images that relate in an arrangement of layers in the panel, where the panel is related to another panel in an outer order.

The language of Rupa, based on the word language, has elements in the form of images and phrases. Image by Primadi Tabrani was later changed to the word of wimba, because he considered that the word image has a meaning that is too broad. Wimba will be composed of the contents of Wimba and the way of wimba (Tabrani, 2012: 135).

Wimba in the visual language of the image can be interpreted as a representative image and not as an abstract or geometric image. The content of the wimba is the object displayed in the picture, while the way of the wimba can be interpreted also as various ways used to visualize an object until the image of the object can tell something meaningful (Tabrani, 2012: 75).

Visual language according to Primadi Tabrani has some ways to display images in addition to the way of the wimba, namely the inner and outer layout (Tabrani, 2012: 75-76). Inner layout is a series or arrangement of various kinds of wimba in a scene or sequence. Outer layout is a series of orders and/or the way the wimba are arranged sequentially on a frame (panel) with another frame so that the sequence is able to tell a story.

\section{Structure of Silent Manga}

Silent manga has all the supporting elements but the difference is in the absence of phonogram elements. Phonograms in conventional comics are used to describe those visualized by images. In the silent manga, the images are arranged in such a way that they follow a certain storyline.

Because without a phonogram, then the picture is required to be able to speak. Comics required to be juxtaposed or made parallel between panels then it is also required that the visual between the panels are mutually interchange with dialogue. To read the dialogue, the tendency to use Primadi Tabrani's theoretical language theory is more appropriate, especially in the inner and outer layout.

Based on the theory of Scott McCloud and Hikmat Darmawan which states that in addition to drawing and writing, there are elements that should be included such as symbols are arranged or displayed deliberately to convey the information so as to generate reaction from the reader.

This silent manga case study uses a sample by comic artists named Mage (Indonesia) with the title "New Haircut" and Roberto F. (Brazil) with the title "Play". In accordance with the layout of the manga panel, then the reading begins from the top right to the bottom left.

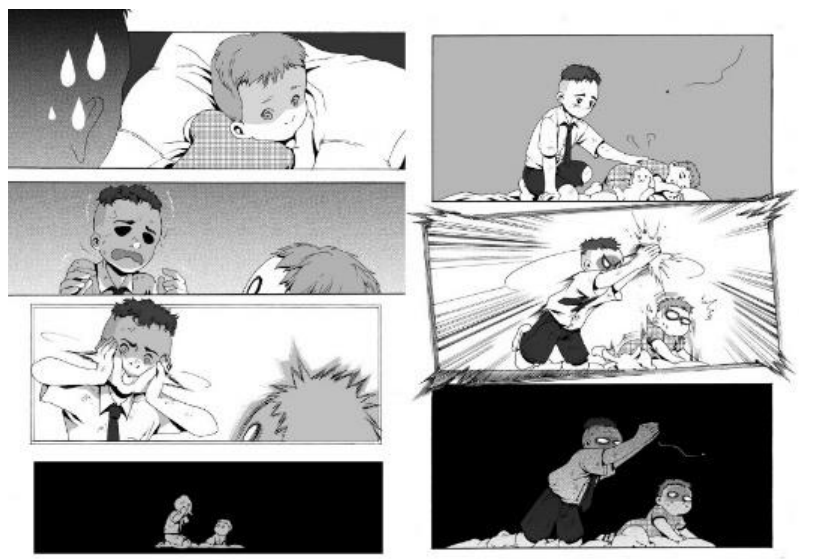

Figure 3. Silent manga by Mage with the title New Haircut, page 6-7. 


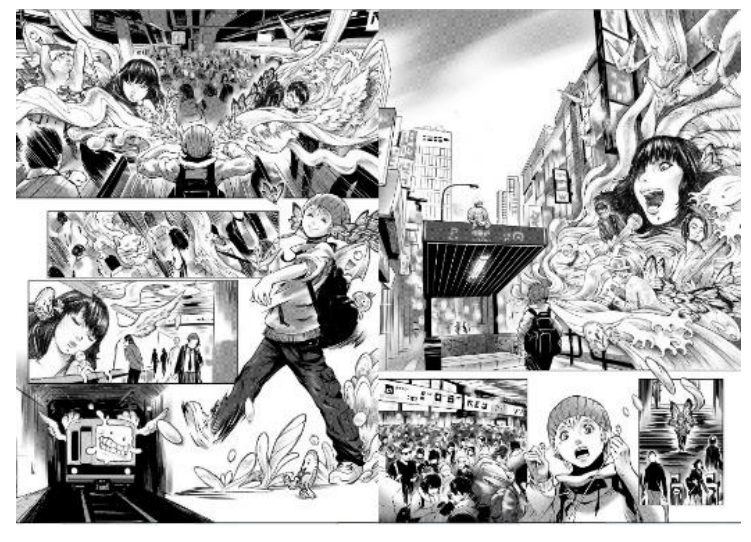

Figure 4. Silent manga by Roberto F. with the title Play, page 2-3.

Manga of New Haircut tells the story of a child with a new haircut that feels weird and becomes a joke but on the other hand even able to calm his sister. The exciting part of this manga is an expressive moment when the character tries to keep mosquitos from causing her sister to wake up. The inner expressions that appear in each panel without displaying phonograms of either caption, dialogue or onomatopoeia. But the dialogue awakens from the visual relation between panels with the juxtaposition based on the story line. The use of character expressions is instrumental in building the reader's interpretation, as is the use of a highly expressive second panel. Dialogue is also generated through the development of character emotions through tone and texture space in each panel.

Manga of Play tells about the imagination of the enjoyment from a child who enjoys music from his earphones. The relation of outer layout is almost similar to New Haircut manga, but what distinguishes them is in the expression in the manga boldly displaying the doodle as the visual language of the music being enjoyed by the child's character. The interpretation that the doodle is the visual language of the music is displayed when the visual is out of the child's ear. It is reinforced in the third panel where there is a moment the child is removing the earphone but the doodle is not displayed.

\section{Conclusion}

Cohesion and the coherence between visual elements that interchange with dialogue in the form of relationship between illustration and symbol. This occurs as a form of relationship between all the comic elements in one panel, except phonogram, as a form of inner layout. And the relationship that occur between panels by following a particular story plays a role as the outer layout. Thus, the phonogram constituent elements in silent manga are not present in the works, but are replaced by elements of images which themselves have spoken through facial expressions, gestures, visual elements, and supporting symbols. Besides that, the non-visual elements such as plot also greatly affect the legibility of comics contextually. So, through these two perspectives can be said that silent manga is one of the assets in the comic constellation.

\section{REFERENCES}

[1] Budiman, Kris, Semiotika Visual: Konsep, Isu, dan Problem Ikonisitas. Yogyakarta: Jalasutra, 2012.

[2] Dharmawan, Hikmat, How to Make Comics Menurut Para Master Komik Dunia. Jakarta: Bentang Pustaka, 2012.

[3] Denzin, Norman K., Lincoln, Yvonna S., Handbook of Qualitative Research terjemahan Dariyatno et.al., Yogyakarta: Pustaka Pelajar, 2009.

[4] Eisner, Will, Comic and Sequential Art. Florida: Poorhouse Press, 1985.

[5] Mataram, Sayid, Bahasa Rupa Komik Indonesia: Studi Kasus Komik Wayang Karya R.A. Kosasih. Institut Seni Indonesia Surakarta, 2014.

[6] McCloud, Scott, Memahami Komik terjemahan S. Kinanti. Jakarta: Kepustakaan Populer Gramedia, 2001.

[7] Saraceni, Mario, The Langue of Comics. New York: Routledge, 2003.

[8] Tabrani, Primadi, Bahasa Rupa. Kabupaten Bandung: Penerbit Kelir, 2005.

[9] www.manga-audition.com 